\title{
STUDY ON THE IRRADIA TION EFFECT S ON IRON NITRIDE BY HIGH ENERGY ELECTRONS AND IONS AT THE ATOMIC LEVEL
}

\author{
H. HASHIMOTO*, Z.Q. LIU*, T. SAKATA**, H. MORI**, M. SONG***, H. YASUdA***, K. FURUYA*** \\ *Department of Mechanical Engineering, Okayama University of Science, Okayama 700-0005, Japan \\ **Research Center of UHVEM, Osaka University, Osaka 565-0871, Japan \\ ***Nanomaterials Laboratory, National Institute for Materials Science, Tsukuba 305-0003, Japan
}

The irradiation effects of high energy electrons and ions on the nitride in the compound layer of gas ion-nitrided pure iron, were studied by illuminating of $400 \mathrm{KeV}, 1 \mathrm{MeV}$ and $2 \mathrm{MeV}$ electrons and injecting of $100 \mathrm{KV}$ Xe ions in high voltage electron microscope (HVEM). The change of grain size, destruction of crystal lattices, formation of holes and bubbles, as well as the irradiation induced phase transformation, were investigated using transmission electron microscopy (TEM) and high resolution electron microscopy (HREM).

$\gamma^{\prime}-\mathrm{Fe}_{4} \mathrm{~N}$ nitride was irradiated with $400 \mathrm{KeV}$ electrons with the dose rate of $6.8 \times 10^{23} \mathrm{e} / \mathrm{m}^{2} \mathrm{sec}$ for 210 minutes. Extra spots appeared in the diffraction pattern and became sharp as shown in Fig1a to Fig.1c. The original HREM image after 7 minutes irradiation (Fig.1d) changed to a big configuration image after 118 minutes irradiation (Fig.1e). The extra spots in Fig.1c and the HREM image in Fig.1e were proved coming from $\mathrm{Fe}_{3} \mathrm{O}_{4}$ oxide, which was formed in $\mathrm{Fe}_{4} \mathrm{~N}$ nitride with the cubic-to-cubic orientation relationship. A new $\gamma^{\prime}-\mathrm{Fe}_{4} \mathrm{~N}$ nitride was also irradiated with $1 \mathrm{MeV}$ electrons with the dose rate of $1.8 \times 10^{24} \mathrm{e} / \mathrm{m}^{2} \mathrm{sec}$ for 480 minutes. In spite of the formation of $\mathrm{Fe}_{3} \mathrm{O}_{4}$ oxide, the nanosized circular contrast presented in the original grain as shown in Fig.2, which indicates the destruction of irradiation on the crystal lattices.

$2 \mathrm{MeV}$ electron irradiation was carried out on $\varepsilon-\mathrm{Fe}_{2-3} \mathrm{~N}$ nitride with the dose rate of $6.3 \times 10^{24} \mathrm{e} / \mathrm{m}^{2} \mathrm{sec}$ for 35 minutes. With increasing the irradiation time, the specimen crystals had been heavily distorted with local bending, and the crystal lattice structures also changed locally. The original grains with the size of 400 600nm in the specimen, had changed to 3-10nm grains with distorted crystal lattices in the heavily damaged area. Some of the crystal lattices overlapped and also joined closely to each other. Moreover, the circular thin regions of 3-5nm in diameters were also produced. Some 2-3nm size areas showing complicated crystal structure images, had been analyzed with Fourier transformation and inverse FFT by selecting the known spots. The HREM image and the diffraction pattern before and after irradiation were shown in Fig.3a and Fig.3b, respectively. It is concluded that the $\mathrm{Fe}_{3} \mathrm{O}_{4}$ oxide transformed from $\varepsilon-\mathrm{Fe}_{2-3} \mathrm{~N}$ nitride with the orientation relationship of $(110) \varepsilon / /(2-20) \mathrm{Fe}_{3} \mathrm{O}_{4}$ and $[1-11] \varepsilon / /[001] \mathrm{Fe}_{3} \mathrm{O}_{4}$.

After 15 minutes irradiation of $100 \mathrm{KV}$ Xe ions with the dose rate of $1.27 \times 10^{17} \mathrm{ions} / \mathrm{m}^{2} \mathrm{sec}$ for 15 minutes, $\gamma^{\prime}-\mathrm{Fe}_{4} \mathrm{~N}$ single crystal changed to small crystals in size of $1-5 \mathrm{~nm}$ with various orientations within the range of 45 degree (see Fig.4). Compared with electron irradiation, the formation of $\mathrm{Fe}_{3} \mathrm{O}_{4}$ oxide was not observed under Xe ion irradiation, which seems to be due to the different irradiation effect between electrons and ions on the iron nitride specimen. 

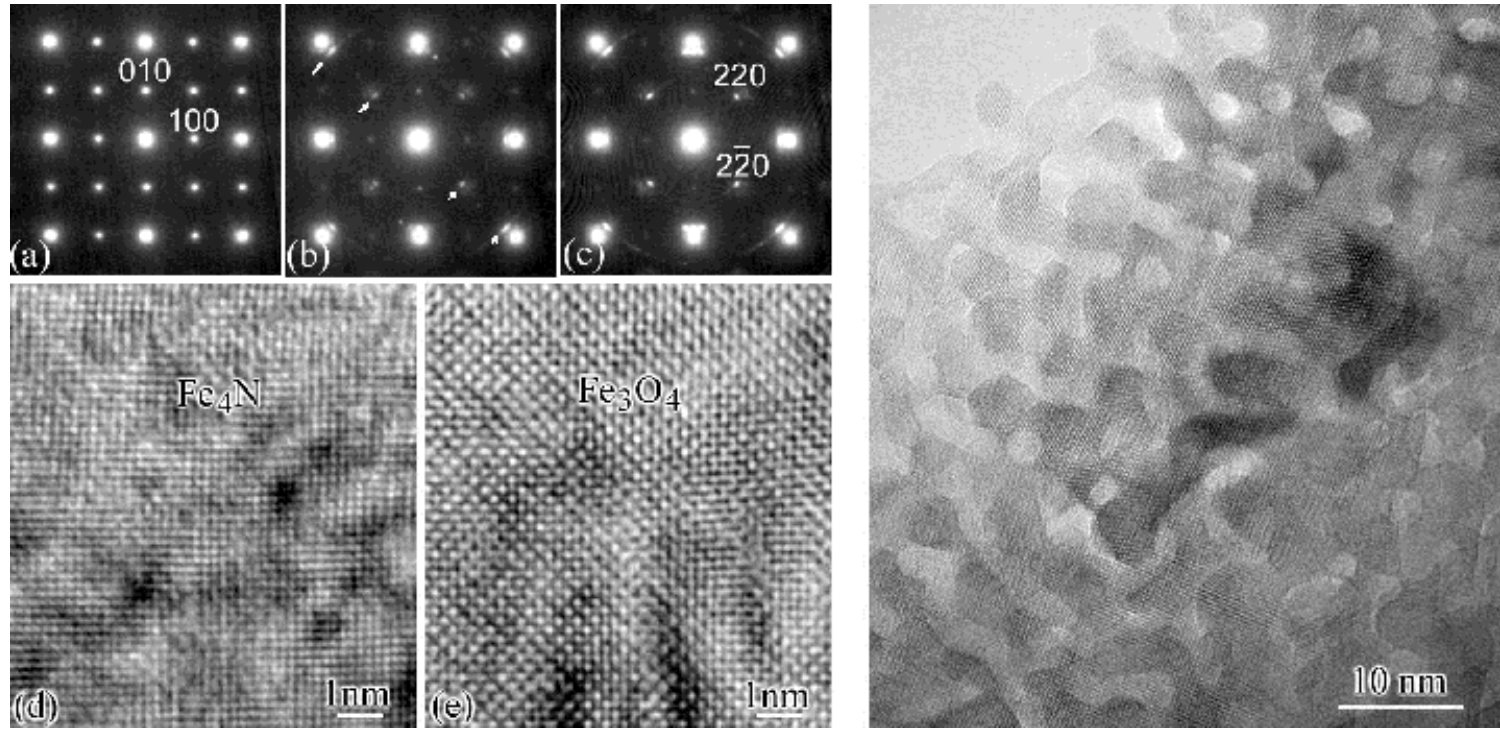

Fig.1 $\gamma^{\prime}-\mathrm{Fe}_{4} \mathrm{~N}$ irradiated by $400 \mathrm{KeV}$ electrons with (a) 0, (b) 64, (c) 123, (d) 7, and (e) 118minutes.

Fig.2 The image of $\gamma^{\prime}-\mathrm{Fe}_{4} \mathrm{~N}$ nitride irradiated by $1 \mathrm{MeV}$ electrons.
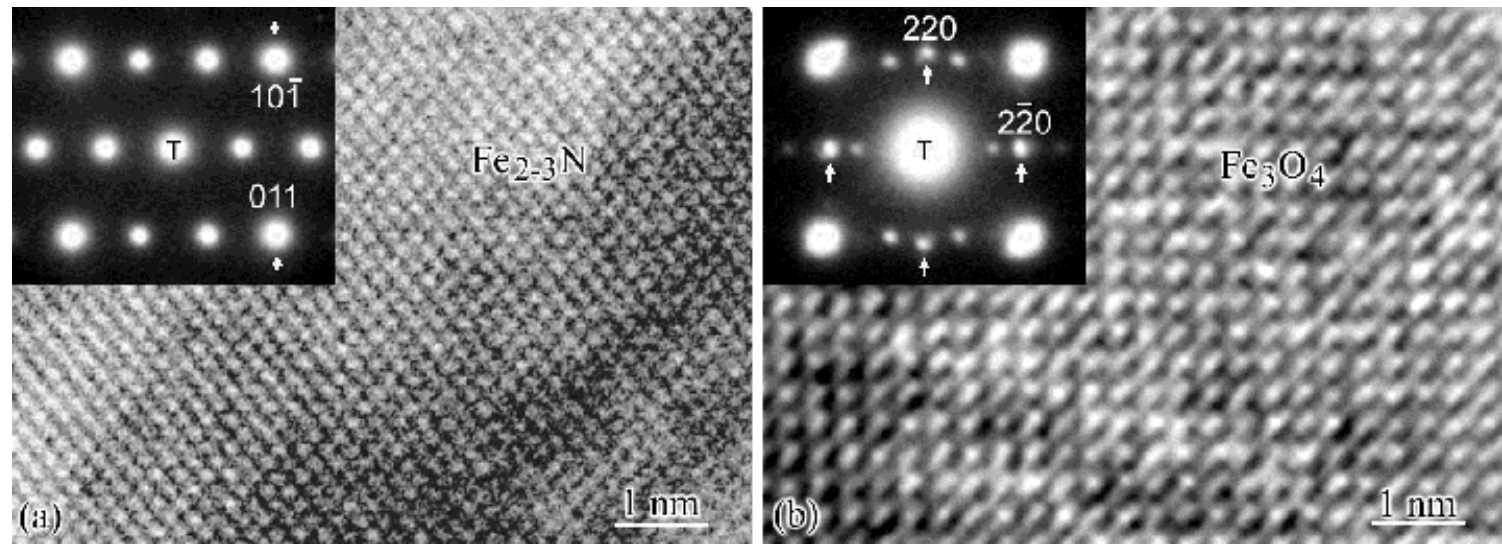

Fig.3 Initial HREM image and diffraction pattern of $\varepsilon-\mathrm{Fe}_{2-3} \mathrm{~N}$ nitride (a) and the formation of $\mathrm{Fe}_{3} \mathrm{O}_{4}$ oxide due to the $2 \mathrm{MeV}$ electron irradiation (b).

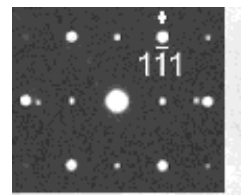

(a)

Fig.4 Bright field image and diffraction pattern of $\gamma^{\prime}-\mathrm{Fe}_{4} \mathrm{~N}$ nitride before (a) and after (b) $100 \mathrm{KV} \mathrm{Xe}$ ion irradiation.

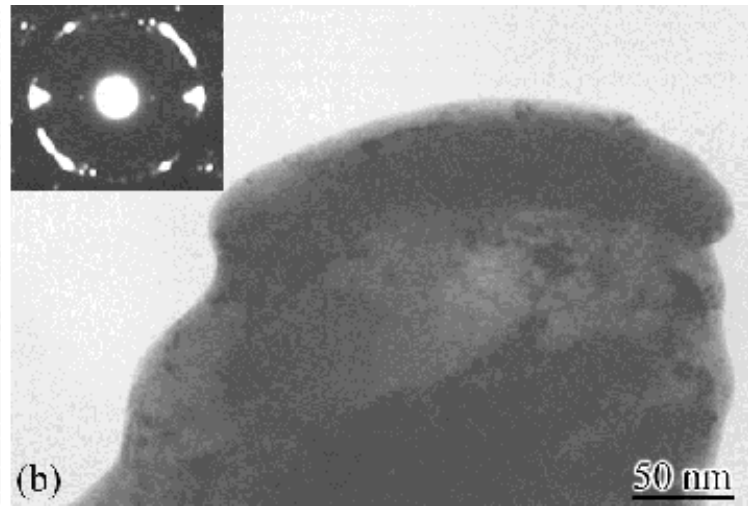

$50 \mathrm{~mm}$ 